\title{
Utilização de Sistema de Informação Geográfica como ferramenta para gestão do monitoramento da qualidade do ar na Região Metropolitana do Rio de Janeiro
}

\author{
Use of Geographic Information System as a tool for the management \\ of air quality monitoring in the metropolitan area of Rio de Janeiro state
}

\section{Eduardo Monteiro Martins', Júlio Domingos Nunes Fortes², Gilberto Pessanha Ribeiro³, Marcus Felipe Mourão Pereira ${ }^{4}$}

\begin{abstract}
RESUMO
A preocupação com a gestão da qualidade do ar na cidade do Rio de Janeiro tem aumentado nos últimos anos devido aos grandes eventos que a cidade irá receber em um futuro próximo. A utilização de Sistema de Informação Geográfica como uma ferramenta para a gestão da qualidade do ar foi avaliada neste trabalho. Foi feita uma nova delimitação das bacias aéreas com a utilização de dados digitais que proporcionou o surgimento de três novas bacias aéreas e a alteração da configuração espacial das bacias aéreas existentes.
\end{abstract}

Palavras-chave: bacias aéreas; qualidade do ar; sistema de informação geográfica; poluição atmosférica.

\begin{abstract}
The concern with the air quality management in the city of Rio de Janeiro has increased in recent last years due to the great events that this city will receive in the near future. The use of a Geographic Information System as a tool for the air quality management was evaluated in this work. A new delimitation of air basins was proposed using the digital data suggesting the appearance of three new air basins and the change of the spatial configuration of the existing air basins.
\end{abstract}

Keywords: air basins; air quality; geographic information system; air pollution.

\section{INTRODUÇÃO}

A qualidade do ar em grandes cidades do mundo é responsável por causar diversos problemas ambientais e, também, na saúde da população. As metrópoles são áreas com alta densidade populacional, elevada atividade econômica e muitas emissões de poluentes. São áreas estratégicas para o controle da poluição e onde os benefícios na gestão da qualidade do ar são máximos (MOLINA \& MOLINA, 2004; GURJAR \& LELIEVELD, 2005; CHAN \& YAO, 2008).

As diferenças na topografia, condições meteorológicas e características de emissão de poluentes levam a significativas diferenças na qualidade do ar dessas cidades, assim como os impactos nas suas populações (PARRISH et al., 2011).
No Brasil, a Região Metropolitana do Rio de Janeiro (RMRJ) é a que apresenta a maior densidade demográfica com uma taxa de urbanização próxima de 99\%. Apresenta ainda a segunda maior concentração de população, onde veículos e indústrias são responsáveis por sérios problemas na qualidade do ar da região. Entretanto, essa região metropolitana tem uma topografia bastante acidentada, uma grande quantidade de morrotes com altitudes variando entre 30 e 100 metros e os maciços da Tijuca e da Pedra Branca, além de parte da Serra do Mar. Essa topografia complexa faz com que a dispersão dos poluentes seja bastante comprometida, principalmente em dias com inversões térmicas com alturas inferiores a 100 metros (INEA, 2009).

O Rio de Janeiro está passando por uma série de transformações devido aos grandes eventos que serão realizados na cidade, como a

'Professor Adjunto da Faculdade de Engenharia da Universidade do Estado do Rio de Janeiro (UERJ) - Rio de Janeiro (RJ), Brasil. 2 Professor Visitante da Faculdade de Engenharia da UERJ - Rio de Janeiro (RJ), Brasil.

${ }_{3}^{3}$ Professor Adjunto do Departamento de Ciências do Mar da Universidade Federal de São Paulo (UNIFESP) - Santos (SP), Brasil.

${ }^{4}$ Mestre em Engenharia Ambiental pelo Programa de Pós Graduação em Engenharia Ambiental da UERJ - Rio de Janeiro (RJ), Brasil.

Endereço para correspondência: Eduardo Monteiro Martins - Rua São Francisco Xavier, 524 - 20550-900 - Rio de Janeiro (RJ), Brasil - E-mail: edmmartins@gmail.com

Recebido: 07/09/13 - Aceito: 17/02/14 - Reg. ABES: 1237 
Copa do Mundo, os Jogos Olímpicos e os Jogos Paralímpicos. Com esse cenário, a Cidade do Rio de Janeiro e a sua região metropolitana são focos de grandes preocupações ambientais, dentre as quais podemos destacar a qualidade do ar e seu monitoramento.

Após os Jogos Olímpicos de Pequim em 2008, onde sérios problemas com a qualidade do ar foram identificados e diversos estudos sobre o assunto foram realizados, ficando evidente a preocupação mundial com a qualidade do ar na cidade do Rio de Janeiro (CAI \& XIE, 2011; WANG \& XIE, 2009; SCHLEICHER et al., 2012; STREETS et al., 2007).

O Comitê Olímpico Brasileiro (COB), no dossiê de candidatura da Cidade do Rio de Janeiro como Cidade Sede, firmou uma série de compromissos ambientais. Entre eles constam propostas de monitoramento e gerenciamento da qualidade do ar, prevendo o aumento do número de estações de monitoramento e aumento do controle de emissões de poluentes (RIO DE JANEIRO, 2009).

Uma série de investimentos tem sido feita para a melhoria da qualidade do ar. Podemos destacar entre eles a criação de vias expressas com o objetivo de reduzir a quantidade de congestionamentos e aumentar a velocidade média dos veículos, melhoria nos transportes coletivos e ainda o aumento da rede automática de monitoramento dos poluentes atmosféricos.

No estado do Rio de Janeiro a qualidade do ar é monitorada desde 1967, quando foram instaladas as primeiras estações de medição e monitoramento (INEA, 2008). Na década de 1980 foram delimitadas áreas de monitoramento com intenção de contribuir para a melhoria da qualidade do ar na região metropolitana (INEA, 2008). No estabelecimento dos limites dessas áreas foram utilizadas altitudes de 100 metros, nas cartas topográficas, para gerar os limites onde a topografia tem grande influência nos fenômenos de dispersão dos poluentes (INEA, 2008).

Atualmente, o monitoramento de poluentes atmosféricos é feito pela rede automática do Instituto Estadual do Ambiente (INEA), pela rede da Secretaria Municipal de Meio Ambiente da Cidade do Rio de Janeiro (SMAC) e pela rede privada, que é de responsabilidade de grandes empresas que causam significativos impactos na qualidade do ar.

No monitoramento da poluição atmosférica, a grande preocupação é a manutenção da qualidade do ar no interior das bacias aéreas, garantindo que a concentração dos poluentes fique dentro dos níveis definidos como aceitáveis. Os padrões de qualidade do ar no Brasil são regulamentados pela Resolução CONAMA 03/90 (CONAMA, 1990).

Por analogia ao conceito de bacia hidrográfica, estabeleceu-se em português a expressão "bacia aérea" para designar áreas em que o relevo, as correntes eólicas e, consequentemente, a dispersão dos poluentes do ar determinem a extensão dos impactos diretos e indiretos das atividades humanas em relação à qualidade do ar. Essas áreas, delimitadas pela topografia e pelos espaços aéreos verticais e horizontais, constituem uma bacia aérea. Durante muitos anos, a antiga Fundação Estadual de Engenharia do Meio Ambiente (FEEMA), atual Instituto Estadual do Ambiente (INEA), utilizou a nomenclatura bacias aéreas para tratar das áreas de gestão da qualidade do ar na Região Metropolitana do Rio de Janeiro. Atualmente, o INEA utiliza o termo sub-regiões e adota o mesmo conceito que foi utilizado para a delimitação das bacias aéreas. Essas sub-regiões são unidades de gerenciamento da qualidade do ar para a RMRJ. A ideia dessas unidades de gerenciamento da qualidade do ar se aplica muito bem para a RMRJ (INEA, 2009; SALES, 1980).

Com o desenvolvimento da tecnologia e da informática, tornou-se possível armazenar e representar as informações em ambiente computacional, abrindo espaço para o aparecimento do geoprocessamento. Um Sistema de Informação Geográfica (SIG) é uma ferramenta com aplicações em diferentes áreas e pode ser utilizado para auxiliar na gestão de problemas ambientais. Uma vantagem do SIG é a eficiência com que ele pode integrar os dados necessários a determinado projeto, que podem ser encontrados em diferentes formatos, mapas, tabelas, cartas, fotos aéreas, imagens de satélite e conjuntos de dados digitais, em um formato compatível para a análise (RIBEIRO, 2005).

A utilização de SIG como ferramenta de gerenciamento da qualidade do ar tem sido frequentemente aplicada em estudos de diversos problemas relativos à poluição atmosférica de centros urbanos (JENSEN, 1999; JENSEN, 1998; PULIAFITO et al. 2003; LIN \& LIN, 2002). Os SIG têm sido utilizados para integrar a análise espacial de dados e modelos de qualidade do ar (JIN \& FU, 2005; REBOL) \& STURM, 1999).

Este trabalho tem como objetivo o estabelecimento da configuração espacial de bacias aéreas ou sub-regiões na RMRJ e adjacências, a partir de dados digitais, com o suporte do SIG, potencializando as análises espaciais envolvidas.

\section{METODOLOGIA}

No desenvolvimento do SIG para o suporte na gestão da qualidade do ar na RMRJ, foram reunidos os dados cadastrais das estações de monitoramento fornecidos pelo INEA e pela SMAC, a série temporal de imagens de satélite para caracterização da área de estudo, as bases cartográficas necessárias para a delimitação das bacias aéreas e análises espaciais, além de dados característicos do comportamento dos ventos e da altura da camada de mistura.

Foi elaborado um banco de dados georreferenciados, em atendimento aos requisitos de mapeamento digital dos limites das bacias aéreas fazendo uso das bases cartográficas digitais do Instituto Brasileiro de Geografia e Estatística (IBGE), na escala de 1:50.000, disponibilizadas pelo INEA, imagens de média resolução Landsat dos anos 2000, 2006 e 2010, conseguidas gratuitamente através do site do Instituto Nacional de Pesquisas Espaciais (INPE), dados temáticos e cadastrais do INEA e da SMAC, dados históricos de monitoramento das inversões térmicas (altura da camada de mistura) disponibilizados gratuitamente no site do Departamento de Ciências Atmosféricas da Universidade de Wyoming 
(UNIVERSITY OF WYOMING, 2012) e de condições meteorológicas (ventos) obtidos gratuitamente através do sistema de geração e disponibilização de informações climatológicas do Instituto de Controle do Espaço Aéreo (ICEA, 2012). O processamento das imagens de satélite e as edições vetoriais e espacialização dos dados temáticos e cadastrais do INEA e da SMAC tiveram como ferramenta básica o sistema ArcGIS (ESRI). O ArcGIS é um pacote de softwares da Environmental Systems Research Institute (ESRI), de elaboração e manipulação de informações vetoriais e matriciais para o uso e gerenciamento de bases temáticas. O ArcGIS disponibiliza, em um ambiente de SIG, uma gama de ferramentas de forma integrada e de fácil utilização (MITCHELL, 2005).

De posse das bases vetoriais digitais fornecidas pelo INEA, foram realizados diversos processamentos para separação de importantes dados para a pesquisa. Para caracterização e limitação da área de estudo foi utilizada a base vetorial de limite geopolítico em que foram separados os municípios pertencentes à RMRJ. São componentes da RMRJ os municípios do Rio de Janeiro, Belford Roxo, Duque de Caxias, Guapimirim, Itaboraí, Japeri, Magé, Nilópolis, Niterói, Nova Iguaçu, Paracambi, Queimados, São Gonçalo, São João de Meriti, Seropédica, Mesquita e Tanguá. Os municípios de Maricá e Itaguaí também foram incluídos devido à forte relação que esses municípios têm com a dinâmica da região metropolitana.

A representação do relevo é de fundamental importância para o estudo proposto. Sendo que essa é uma das principais características da RMRJ, já que dificulta a dispersão dos poluentes emitidos e carregados para a o interior das bacias aéreas.

Foram separadas as curvas de nível das cotas de 100, 200 e 300 metros escolhidas para criação das novas bacias aéreas, de acordo com as análises dos dados de altura da camada de mistura e inversão térmica que serão apresentados posteriormente. As bacias aéreas criadas originalmente foram delimitadas utilizando a cota de 100 metros e sem os recursos digitais presentes atualmente.

Com base no inventário de fontes emissoras na RMRJ realizado pelo INEA em maio de 2004, foram separadas todas as vias caracterizadas como as principais vias estruturais e artérias de circulação de veículos automotores. Dessa forma, foi criada uma representação vetorial de todas as vias de grande circulação onde ocorrem diariamente grandes congestionamentos.

Com as curvas de nível das cotas de 100, 200 e 300 metros separadas, foram vetorizadas as bacias aéreas a partir dos dados digitais. O trabalho foi realizado em ambiente computacional e seguiu a mesma metodologia aplicada anteriormente. As curvas de nível que representam o relevo foram unidas por meio do processo de vetorização criando as barreiras físicas. Após a união dessas curvas, foram gerados os polígonos, e com o auxílio das ferramentas do software ArcGis foi possível realizar o cálculo da área de cada uma das referidas bacias.

Neste trabalho foram consideradas as estações de monitoramento automáticas do INEA, a Rede Automática da Secretaria Municipal do
Meio Ambiente e a rede automática de empresas privadas que fazem o monitoramento do impacto atmosférico devido as suas atividades. Foram consideradas também as principais vias de emissão de poluentes por fontes móveis.

\section{RESULTADOS E DISCUSSÃO}

Os resultados apresentados são da análise espacial realizada utilizando o software ArcGis, na qual a visualização de todos os dados juntos no SIG possibilitou algumas considerações importantes. Com essas ferramentas computacionais foi possível a realização de cálculos de área, volume, verificação de espaços não ocupados, direção de ventos e avaliação dos impactos das inversões térmicas, quando analisadas em conjunto com as barreiras físicas. Assim, os fenômenos externos aos estudos de monitoramento, já realizados para o entendimento da dinâmica da poluição atmosférica na RMRJ, puderam ser vetorizados e analisados espacialmente.

As ocorrências de inversões térmicas são importantes para a avaliação das cotas que foram utilizadas como limite vertical das bacias aéreas. No total, foram verificadas 148 inversões inferiores a 300 metros no período de junho de 2010 até maio de 2011. Essas inversões foram separadas seguindo o critério de faixas de altitude e estações do ano. Foram definidas as faixas de avaliação com inversões inferiores a 300 metros e superiores a 200 metros, inferiores a 200 metros e superiores a 100 metros e a faixa com inversões inferiores a 100 metros. A Tabela 1 apresenta os dados organizados pelos critérios de altitude e com os seus valores percentuais em relação ao total de inversões ocorridas. O inverno foi a estação do ano que apresentou o maior percentual de inversões térmicas, com altura inferior a $300 \mathrm{~m}$.

Com os dados vetorias digitais das curvas de nível de 100 metros foram gerados quatro polígonos que representam as bacias aéreas existentes (Bacias I, II, III e IV) e três novos polígonos representando as bacias aéreas que foram denominadas de Bacia Aérea da Zona Sul, Bacia Aérea de Niterói e Bacia Aérea de Maricá.

A Figura 1 apresenta na cor vermelha a nova configuração das bacias aéreas da RMRJ para a altitude de 100 metros comparada com a antiga delimitação dessas regiões com o uso de carta topográfica.

Após a realização do cálculo das áreas com as ferramentas computacionais, foi possível observar que ocorreu um aumento aproximado da área das Bacias Aéreas I, III e IV em 23, 17 e 66\%, respectivamente,

Tabela 1 - Número de inversões térmicas por faixas de altitude ocorridas entre junho de 2010 e maio de 2011.

\begin{tabular}{l|c|c|c|c} 
& \multicolumn{4}{|c}{ Intervalos em metros } \\
\hline Altitudes & $300-200$ & $200-100$ & 100 & Total \\
\hline Ocorrências & 32 & 51 & 65 & 148 \\
\hline$\%$ & 21,62 & 34,46 & 43,92 & 100 \\
\hline
\end{tabular}


e redução da área da Bacia Aérea II em 4\%, além do surgimento dos três novos polígonos. Na Tabela 2 são apresentadas as áreas antigas e novas das bacias aéreas, e um comparativo entre elas.

A Bacia Aérea I, após a vetorização realizada com dados digitais, apresentou um valor de área de cerca de $1.057 \mathrm{~km}^{2} \mathrm{e}$ um perímetro de aproximadamente $335 \mathrm{~km}$. Nessa bacia aérea estão localizadas as rodovias Presidente Dutra e Rio-Santos, grande parte da Avenida Brasil e uma indústria siderúrgica de grande porte.

A Bacia Aérea II revelou uma área de cerca de $182 \mathrm{~km}^{2}$ e um perímetro de aproximadamente $136 \mathrm{~km}$, e envolveu as regiões administrativas de Jacarepaguá e Barra da Tijuca, no município do Rio de Janeiro. Nessa bacia aérea estão localizadas a Avenida Ayrton Sena, a Avenida das Américas e a Linha Amarela, que foram relacionadas no inventário

Tabela 2 - Áreas das bacias novas e antigas para a altitude de 100 metros.

\begin{tabular}{l|c|c|c}
\hline Bacias & Área antiga $\left(\mathrm{km}^{2}\right)$ & Área nova $\left(\mathrm{km}^{2}\right)$ & $\%$ \\
\hline Bacia Aérea I & 857,97 & 1057,77 & 23 \\
\hline Bacia Aérea II & 190,08 & 182,54 & -4 \\
\hline Bacia Aérea III & 868,87 & 1018,31 & 17 \\
\hline Bacia Aérea IV & 876,48 & 1451,88 & 66 \\
\hline Bacia Aérea da Zona Sul & - & 24,01 & - \\
\hline Bacia Aérea de Niterói & - & 35,98 & - \\
\hline Bacia Aérea de Maricá & - & 264,65 & - \\
\hline
\end{tabular}

de fontes emissoras de poluentes atmosféricos como vias de grande contribuição na emissão de poluentes.

A Bacia Aérea III apresentou um perímetro de aproximadamente $433 \mathrm{~km}$ e uma área de 1.018 km². Nessa bacia aérea estão localizadas as rodovias Washington Luiz e Presidente Dutra, a Linha Vermelha, a Linha Amarela, um trecho da Ponte Rio-Niterói e grande parte da Avenida Brasil, todas importantes vias de trânsito, que foram relacionadas no inventário de fontes emissoras como contribuintes na emissão de poluentes. Além da contribuição de significativas fontes móveis, temos na Bacia Aérea III o polo industrial de Campos Elíseos, em Duque de Caxias, que contribui significativamente para a degradação da qualidade do ar nessa região. O polo petroquímico de Duque de Caxias apresenta a maior densidade de indústrias não só da RMRJ como também do Estado do Rio de Janeiro, afetando a qualidade do ar da Bacia Aérea III. As indústrias da área de refino de petróleo, estocagem de combustíveis e geração de energia são alguns dos tipos de atividade das indústrias da região (INEA, 2008).

A Bacia Aérea IV revelou um perímetro aproximado de $591 \mathrm{~km}$ e uma área de $1.451 \mathrm{~km}^{2}$. Nessa bacia aérea está localizada a Rodovia BR-101 e está sendo instalado um complexo petroquímico. A Bacia Aérea da Zona Sul engloba os bairros do Leblon, Ipanema, Lagoa, Copacabana, Leme e parte dos bairros da Gávea, Humaitá, Botafogo e Urca. Essa bacia apresentou um perímetro de $30 \mathrm{~km}$ e uma área aproximada de $24 \mathrm{~km}^{2}$. A Bacia Aérea da Zona Sul possui características importantes

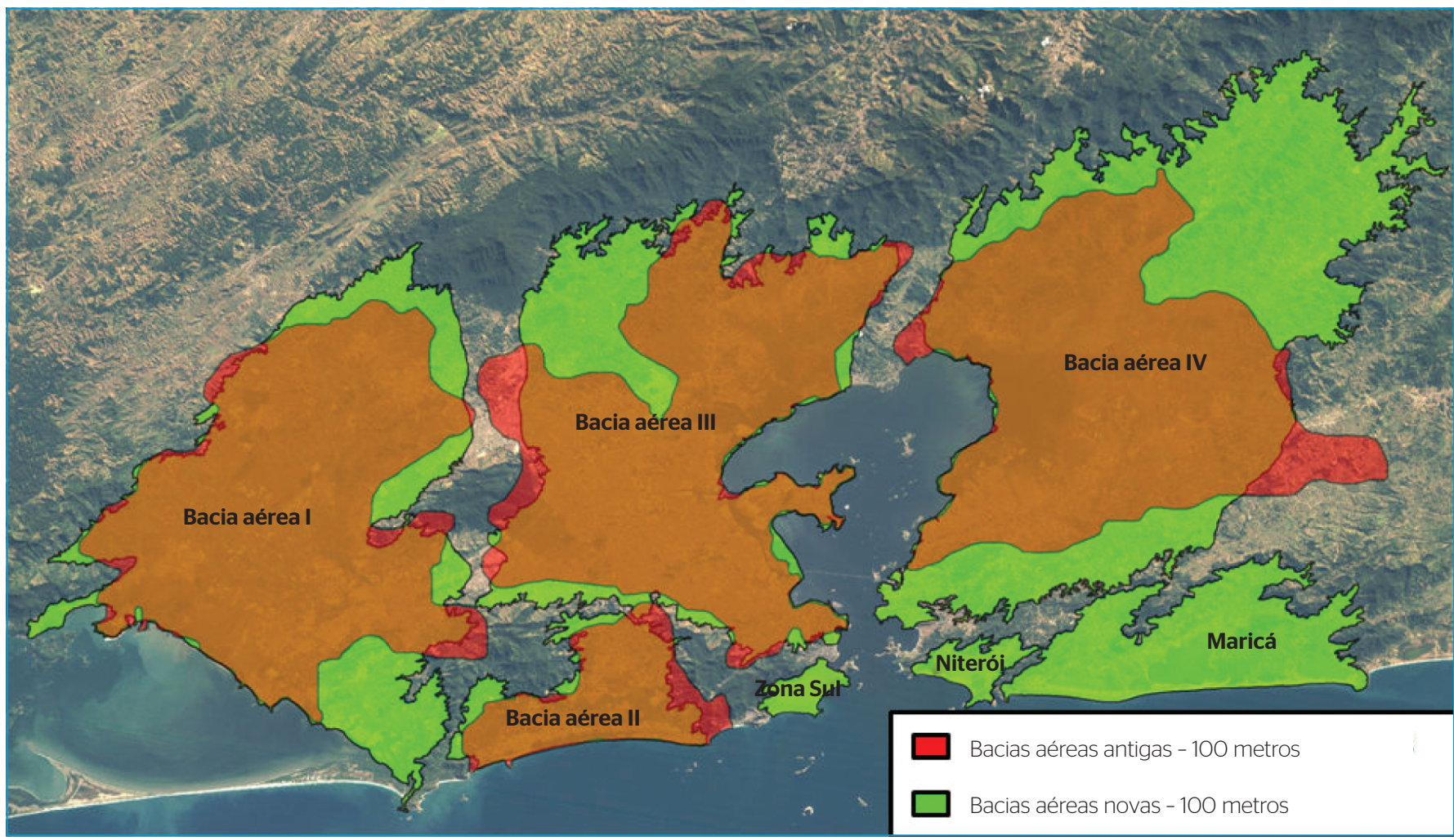

Figura 1 - Configuração espacial das bacias aéreas novas geradas a partir das curvas de nível de 100 metros com dados digitais e das antigas bacias aéreas antigas geradas a partir de cartas topográficas. 
relacionadas ao problema da poluição atmosférica. Ela engloba bairros densamente povoados e registra grande fluxo de veículos por suas vias de trânsito. A existência de ventos vindos do mar e a pequena área são particularidades dessa bacia aérea.

A Bacia Aérea de Niterói revelou uma área de aproximadamente $35 \mathrm{~km}^{2}$ com um perímetro de $49 \mathrm{~km}$ compreendendo os bairros da região oceânica do município de Niterói. A Bacia Aérea de Maricá, que compreende o município de Maricá em quase toda sua totalidade, apresentou uma área de $264 \mathrm{~km}^{2}$ com um perímetro de $176 \mathrm{~km}$.

Com os dados vetorias digitais das curvas de nível de 200 metros, foram gerados 6 polígonos ilustrados na Figura 2. Diferentemente dos polígonos gerados para a altitude de 100 metros, os polígonos das bacias existentes não foram mantidos, e após a vetorização foi observada a junção das Bacias Aéreas I e III. As demais bacias foram mantidas, porém sofreram modificações em suas configurações espaciais.

A configuração espacial das bacias aéreas utilizando os dados vetorias digitais das curvas de nível de 300 metros revelou a junção de todas as bacias e a geração de somente um polígono vazado no seu interior pelas partes mais altas do maciço da Tijuca, da Pedra Branca e de Gericinó.

Utilizando o SIG como ferramenta para caracterizar as áreas de monitoramento dos poluentes atmosféricos, foram gerados layers com os dados cadastrais das estações de monitoramento, onde foi possível ter a visualização da atual distribuição espacial das estações na RMRJ.
Os pontos verdes identificam as estações de monitoramento automáticas do INEA, os pontos amarelos identificam estações automáticas da rede privada instaladas em virtude de grandes empreendimentos licenciados pelo INEA, enquanto que os pontos azuis representam as estações automáticas da prefeitura, como apresentado na Figura 3.

Utilizando o SIG para a visualização da imagem do satélite Landsat, dos dados das estações e dos limites das bacias aéreas para a altitude de 100 metros, foi possível verificar uma maior concentração das estações de monitoramento na Bacia Aérea III, justamente a área com os maiores problemas de qualidade do ar.

\section{CONCLUSÕES}

A gestão da qualidade do ar através da utilização do zoneamento com base no conceito de bacia aérea é de fato indicada para a RMRJ, devido às suas características topográficas particulares, às condições meteorológicas observadas através do monitoramento e ao caráter transfronteiriço de poluentes do ar.

A vetorização dos limites das bacias aéreas, com a utilização de dados digitais e sistemas computacionais, apresentaram melhores resultados do que os limites propostos anteriormente pelo INEA, devido à qualidade do processo e dos dados utilizados, revelando três novas bacias aéreas e significativas alterações nas bacias aéreas existentes, que devem ser consideradas.

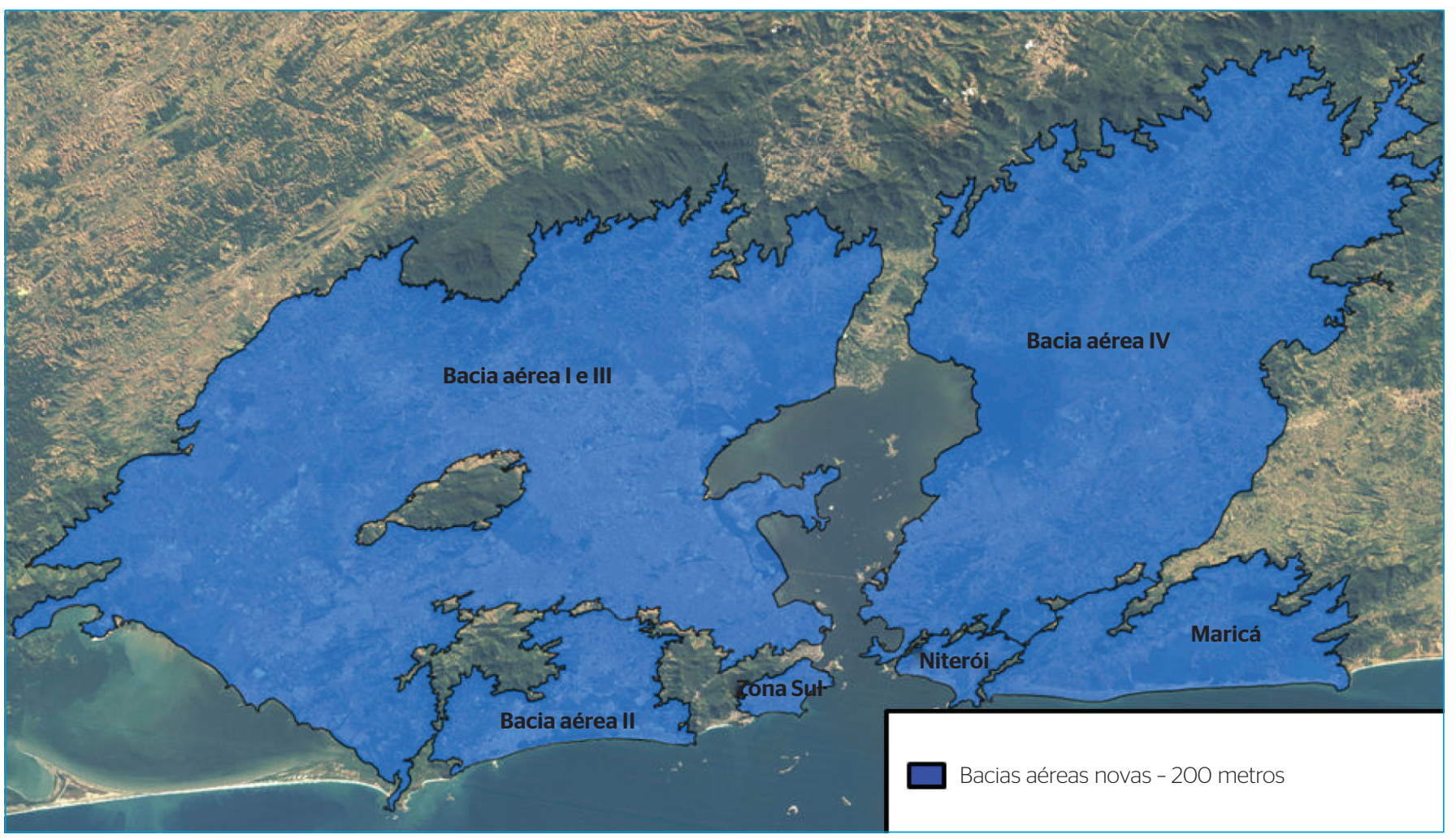

Figura 2 - Configuração espacial das bacias aéreas novas geradas a partir das curvas de nível de 200 metros com dados digitais. 


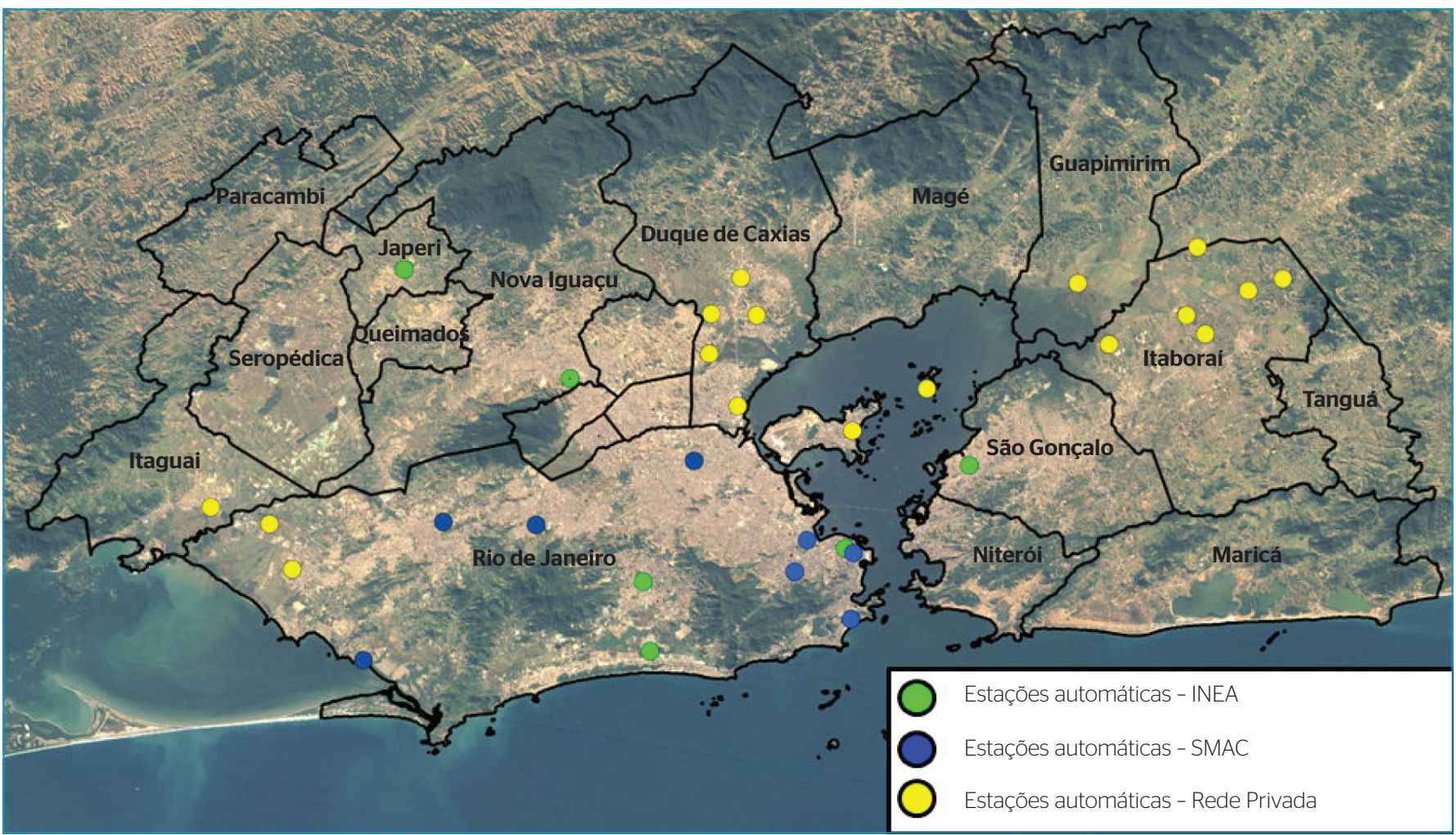

Figura 3 - Distribuição espacial das estações de monitoramento automáticas na Região Metropolitana do Rio de Janeiro.

Os limites das bacias aéreas para a altitude de 100 metros são de fato os mais indicados para a gestão da qualidade do ar sob o conceito de bacias aéreas. Eles representam as áreas mais afetadas durante as ocorrências de fenômenos meteorológicos críticos que comprovadamente ocorrem e que provocam uma maior concentração de poluentes prejudicando a população da RMRJ.

A comparação entre os novos limites das bacias aéreas de 100 metros de altitude e os limites propostos anteriormente pelo INEA revelou o aumento das áreas das Bacias Aéreas I, III e IV em 23, 17 e 66\%, respectivamente, e uma redução da área da Bacia Aérea II em 4\%. Essas alterações de área devem ser consideradas para a expansão da rede de monitoramento e distribuição espacial das estações de monitoramento.
O SIG se mostrou uma ferramenta eficiente para a gestão ambiental da qualidade do ar na RMRJ. Permitiu em ambiente de escritório, por meio de um banco de dados geográficos georreferenciado, a representação dos elementos necessários para a avaliação da configuração espacial das bacias aéreas e proporcionou uma visualização dinâmica da distribuição espacial das estações de monitoramento nas bacias aéreas propostas.

A atualização da base de dados é fundamental para a melhor representação do espaço geográfico e deve ser realizada constantemente, uma vez que muitas transformações na RMRJ são esperadas até o ano de 2016, quando ocorrerão os eventos da Copa do Mundo de Futebol no Brasil e dos Jogos Olímpicos e Paralímpicos na Cidade do Rio de Janeiro.

\section{REFERÊNCIAS}

CAI, H. \& XIE, S. (2O11) Traffic-related air pollution modeling during the 2008 Beijing Olympic Games: the effects of an odd-even day traffic restriction scheme. Science of the Total Environment, v. 409, n. 10, p. 1935-1948

CHAN, C.K. \& YAO, X. (2008) Air pollution in mega cities in China. Atmospheric Environment, v. 42, n. 1, p. 1-42.
CONAMA - Conselho Nacional do Meio Ambiente. (1990) Resolução CONAMA no 3, de 28 de junho de 1990. Dispõe sobre padrões de qualidade do ar, previstos no PRONAR. Diário Oficial da União, 22 de agosto de 1990. Seção I.

GURJAR, B.R. \& LELIEVELD, J. (2005) New directions: megacities and global change. Atmospheric Environment, v. 39, n. 2, p. 391-393. 
ICEA - Instituto de Controle do Espaço Aéreo. (2012) Sistema de Geração e Disponibilização de Informações Climatológicas. Disponível em: <http://clima.icea.gov.br/clima/>. Acesso em: 10 jan. 2012.

INEA - Instituto Estadual do Meio Ambiente do Rio de Janeiro (2008). Relatório Anual da Qualidade do Ar. Disponível em: http://www.inea. rj.gov.br/cs/groups/public/@inter_dimfis_gear/documents/document/ zwff/mde3/ edisp/inea_017062.pdf. Acesso em: 10 set. 2011.

INEA - Instituto Estadual do Meio Ambiente do Rio de Janeiro (2009). Relatório Anual da Qualidade do Ar. Disponível em: http://www.inea. rj.gov.br/cs/groups/public/@inter_dimfis_gear/documents/document/ zwff/mde3/ edisp/inea_017061.pdf . Acesso em: 10 set. 2011.

JENSEN, S.S. (1998) Mapping human exposure to traffic air pollution using GIS. Journal of Hazardous Materials, v. 61, p. 385-392.

JENSEN, S.S. (1999) A geographic approach to modeling exposure to traffic air pol/lution using GIS. Tese (doutorado) - National Environmental Research Institute, Denmark.

JIN, T. \& FU, L. (2005) Application of GIS to modified models of vehicle emission dispersion. Atmospheric Environment, v. 39, n. 34 , p. 6326-6333.

LIN, M.D. \& LIN, Y.C. (2002) The application of GIS to air quality analysis in Taichung City, Taiwan, ROC. Environmental Modelling \& Software, v. 17, n. 1, p. 11-19.

MITCHELL, A. (2005) The ESRI Guide to GIS Analysis Volume 1: Geographic Patterns and Relationships. California: Esri Press.

MOLINA, M.J. \& MOLINA, L.T. (2004) Critical review: megacities and atmospheric pollution. Journal of the Air \& Waste Management Association, n. 54, p. 644-680.

PARRISH, D.D.; SINGH, H.B.; MOLINA, L.; MADRONICH, S. (2011) Air quality progress in North American megacities: a review. Atmospheric Environment, v. 45, n. 39, p. 7015-7025.
PULIAFITO, E.; GUEVARA, M.; PULIAFITO, C. (2003) Characterization of urban air quality using GIS as a management system. Environmental Pollution, n. 122, n. 1, p. 105-117.

REBOLJ, D. \& STURM, P.J. (1999) A GIS based component-oriented integrated system for estimation, visualization and analysis of road traffic air pollution. Environmental Modelling \& Software, v. 14, n. 6, p. 531-539.

RIBEIRO, G.P. (2005) Tecnologias digitais de geoprocessamento no suporte à análise espaço temporal em ambiente costeiro. Tese (doutorado em Geografia) - Universidade Federal Fluminense, Rio de Janeiro.

RIO DE JANEIRO. (2009) Dossiê de candidatura do Rio de Janeiro a sede dos jogos olímpicos e paraolímpicos de 2016. Disponível em: http://www. rio2016.com/sites/default/files/parceiros/dossie_de_candidatura_v1.pdf. Acesso em: 10 jan. 2012.

SALES, J.A. (1980) Dimensionamento da Rede de Monitoramento da Qualidade do Ar. Fundação Estadual de Engenharia do Meio Ambiente (FEEMA). Departamento de Poluição. Divisão de Poluição do Ar. Rio de Janeiro: FEEMA.

SCHLEICHER, N.; NORRA, S.; CHEN, Y.; CHAI, F.; WANG, S. (2012) Efficiency of mitigation measures to reduce particulate air pollution: a case study during the Olympic Summer Games 2008 in Beijing, China. Science of The Total Environment, v. 427-428, p. 146-158.

STREETS, D.G.; FU, J.S.; JANG, C.J.; HAO, J.; HE, K.; TANG, X.; ZHANG, Y.; WANG, Z.; LI, Z.; ZHANG, Q.; WANG, L.; WANG, B.; YU, C. (2007) Air quality during the 2008 Beijing Olympic Games. Atmospheric Environment, v. 41 , n. 3, p. $480-492$

UNIVERSITY OF WYOMING. (2012) Department of Atmospheric Science. Disponível em: <http://weather.uwyo.edu/upperair/sounding. html>. Acesso em: 10 jan. 2012.

WANG, T. \& XIE, S. (2009) Assessment of traffic-related air pollution in the urban streets before and during the 2008 Beijing Olympic Games traffic control period. Atmospheric Environment, v. 43, n. 35, p. 5682-5690. 
